\title{
Development of an Emotional Salary Model: a Case of Application
}

\author{
Victor Daniel Gil Vera ${ }^{1, *}$, Juan Diego Betancur A. ${ }^{1}$, Luis Fernando Quintero', \\ Isabel Cristina Puerta Lópera ${ }^{1}$, Catalina Quintero López ${ }^{1}$ and Javier Sebastían Ruíz Santacruz ${ }^{2}$ \\ 1Department of Psychology, Medellín, Colombia; victor.gilve@amigo.edu.co, \\ juan.betancurri@amigo.edu.co, luis.quinterora@amigo.edu.co, \\ vice.investigaciones@amigo.edu.co,catalina.quinterolo@amigo.edu.co \\ 2Department of Demography, Barcelona, Spain; sruiz@ced.uab.cat
}

\begin{abstract}
Objectives: To determine the dimensions that explain the construction of an emotional salary model that is articulated through the logic of the strategic management of human talent in organisations based in Medellín city. Methods/statistical analysis: This study presents a quantitative approach, a stratified sampling method with an explanatory design that is transversal and non-experimental. The instrument for gathering information was a Likert-scale test questionnaire which was applied to 175 medium-sized companies of Medellín city that have between 51 and 200 workers. Findings: The entrepreneurs think that the salary that they pay is what makes a worker feel satisfied, so that even the implementation of an emotional salary as organisational policy is not relevant, since they do not have empirical evidence to measure the relationship between emotion and salary in the context of considering salary increase that aims at increasing productivity. Application/improvements: An emotional salary model that is adapted to the needs of the companies allows to measure the productivity of the organisation; the general perception is that a healthy company help its personnel strike a balance between work and family.
\end{abstract}

Keywords: Emotion, Human, Management, Organisations, Salary

\section{Introduction}

Global changes, social, economic, and political, and intense competition in the global market, have forced organisations to face myriad internal and external situations that challenge their efficiency and profitability both nationally and globally. To compete in the competitive global market companies need to have a solid organisational structure, competitive products and services, innovative technology, and a skilled human resource pool. At the same time, companies that want to be productive and competitive should seek the consolidation of a committed work team with high capacity to adapt to the changes, to be proactive, and to establish a relationship between the company and the family. To achieve this relationship, companies require a stronger connection between the company management and the workforce in order to develop and implement strategies that strengthen work, increase productivity and profitability, and augment all-round organisational and employee welfare. The emotional salary is a non-economic compensation that complements monetary salaries, where the needs of the partners to be able to cope with the demands of the company is given priority. 1 Among elements considered to be constituents of the concept of emotional salary are flexibility in work schedule, time for training, teleworking, sharing and enjoying spaces to spend quality time with one's family, and so on.

To understand the construct of emotional salary, you must articulate the theories of administration, modern management, and human talent. An explanatory and non-experimental design that was not manipulated by variables was used in the present study which findings are presented in this article. A stratified sample of 175

*Víctor Daniel Gil Vera. Department of Psychology, NBA research group. Universidad Católica Luis Amigó. victor.gilve@amigo.edu.co 
medium-sized enterprises in the productive sector of Medellin city was used for the analysis. The analysis section presents some limitations, including the lack of confidence on the part of employers to accept this type of proposal, as most of them are focused only on financial results and do not have any schemes or programmes that aim to provide the 'emotional' nurturing, which is much needed for the satisfaction of the workforce; in the absence of such initiatives that focus on employees' mental health and emotional well-being, employees eventually get bogged down and burn out if the emotional aspects or needs of their persona aren't nurtured. For example, in a typical work scenario populated by millennials, what counts as important for them over and above monetary salary that they receive includes labour flexibility, style of dress, and constant rotation in their jobs; these are aspects that also affect the consolidation of a work team.

The objective of this article is to define how companies can establish an emotional salary model to allow collaborators the enjoyment of their occupational activities and their family life. This article is divided into six parts. The first part presents a thematic contextualisation; the second part, the problem, justification, research questions, and objectives; the third part, the state of the art and the epistemological fundamentals; the fourth part, the development of the methodology; the fifth part, research results; and the sixth part, conclusions.

\section{Strategic Management of Human Talent}

In the human talent concept, the role of human management areas of leaders involves the construction of a new approach that makes it possible to have relevance within companies, and to lead processes close to the collaborators, observing the human beings in a holistic manner. $\underline{2}$

Within the variables considered for assessing the strategic management area, human talent is a crucial differentiating and competitive factor within companies, the context of a comprehensive management, and the difference in management perceptions about the general business strategy of the company and their strategic approach to utilising the human talent. Analysing this perceptual difference that comes to the fore because of the 'human glance' works well for analysing and understanding and developing ways that companies can implement to improve and strengthen the human factor and develop appropriate labour conditions; conditions that ensure the hygiene and safety of all at the workplace and strengthen both the organisations' business and the work environment. $\underline{3}$

In addition, within the business activities, one of the organisation's tasks, whatever their economic sector and size, is to consider the human talent. This allows to develop and consolidate a structure of the company that can help the company compete better in the markets and achieve results that are positive and contribute to the consolidation and business growth of the organisation. Some factors to consider within the human talent management processes that this area required to fulfil include the following: the needs of the company, defining the required resource, inviting appropriate personnel with the right profile to fill in the vacant position, ensure the chosen staff member has all the required skills for putting out the best performance in the new position; in other words, it is about giving due credence to all these needs and act on them consistently; company must keep looking for collaborators in an ongoing manner who can contribute for the company to grow at an accelerated rate and keep pace with the competition by nurturing and retaining its best talents. $\underline{4}$

Also, strategic management of human talent must be an essential part of, and conceived from, the goals of the organisational strategic plan, in order to get the best collaborators who can help the company achieve its business objectives. The human talent area should change its internal look, that is to say, it should stop being a mere operational aspect of the company and become a more strategic and tactical area of the organisation. $\underline{5}$

\subsection{Humanised Management}

The humanised management process as explained by some scholars ${ }^{\underline{6}}$ is that when the human talent acts as a generator of a competitive process, which contributes to the construction of a company, it ensures company's survival in the market and yield results that allow the organisation to tackle the challenges of the environment as well as the demands of the market; to achieve all of this, organisation needs only a few collaborators who are motivated to perform well and carry out and achieve organisational activities and goals in a timely manner. Today's organisations see their partners as executors of the activities characteristic of the work assigned to them; that indicates a situation where such partners are only concerned about receiving a salary, forgetting as a result 
what truly motivates them and enhances, or helps them realise, their true potential and gain recognition and appreciation, which are just as important as the salary they earn; likewise, you lose sight of the concept that companies must work collaboratively to achieve organisational objectives and initiate steps that strengthen and build a management that is focused on the 'human' element and talent within the organisation and psychological and material well-being of the collaborators' family environment. $\underline{7}$

The humanised management must consider the fundamental aspects to be able to consolidate the dignity of work and the ways and attitude and the spirit with which work is required to be performed-including traits such as partners' enthusiasm and motivation; organisational identity, ethics, and work culture; and partners' values, permanence, and relevance-and respond to what the company expects of the employee to become the input to a humanised management, which in turn creates a stable state or work environment where employees feel motivated to perform better for the company as well as lead their personal lives in a more healthy, emotionally fulfilling, and positive domestic environment. ${ }^{8}$

\subsection{Loyalty of Collaborators}

The need to retain the collaborators is as important as the loyalty of the external customers or buyers. The onus of promoting loyalty of the staff starts from the top management, and it is the responsibility of the management of human talent; in this sense, it must be ensured that there exists an internal policy that ensures that the partners feel and believe they are an important part of the company ${ }^{9}$; in addition, plans should be designed that communicate the strategies, objectives, goals, organisational culture, and mission and vision of the company; empower the internal customer to identify the organisation as an ally and that they are as important as of the company's external customers, competition, and other stakeholders; and promote, establish relationships between the company and the personnel that positively influence and enhance the quality of personal life of the workforce as well as the company's business competitiveness.

The laboral quality is related to factors such as retaining their best-performing partners and providing value to them. Thus, businesses should look for partners to have stability, and to achieve this, you need to establish a space of staff training and development. $\frac{10}{}$ In this way, partners can be evaluated and have fidelity at the time of the decision to withdraw. Equally, it is required on the part of the partners to perform their best for the company, which is entitled to feel pride and satisfaction about their performance; the company's work must enjoy an equal status with the interpersonal relationships that are based on respect and the work dignity.

If a collaborator is satisfied, motivated, and has interest in remaining in the organisation, it is an important factor in gaining and retaining customers; collaborators' interaction with customers reflects their mood, whether pleasant or not; thus, the work of the management is to motivate their partners and ensure they act committed to reflect this motivation in the quality of service provided to the client, which results in a successful organisation, a happy workforce, and a satisfied client. $\underline{11}$ Modern and competitive organisations develop plans to achieve on-time permanence in time, and this needs the company to be efficient; to do this, company may establish indicators that measure the actions of each partner; in this way, the attention of the employee must be within the tactical plan of the organisation to be able to identify which are the aspects of the performance that require and need partners and identify factors that will bring in positive changes and retain the best talent. $\underline{12}$

\subsection{Human Capital}

The human capital is seen as an asset for the organisation and must be considered not only as an individual strength but also as the collective strength of a group of people in pursuit of organisational objectives; the company thus analyses profile factors such as age, expertise, and skills already acquired and need to be developed. To consider the financial cost of these collaborators, company needs to additionally weigh in a set of characteristics that define the productive life of a contributor, such as age, retirement, job changes, diseases, and academic preparation, analysing in a comprehensive and precise manner what it needs to fulfil its objectives. $\underline{\underline{13}}$

One of the exponents representative of human capital was, $\underline{14}$ who believed that the processes of global change, presented in the life and work of a collaborator, impact the purpose of the company, from quality to knowledge management to innovation; this means it is not about just analysing company plans using the numerical measure of the cost of employees, but analysing their contribution 
from the point of its growth trajectory, academic preparation, and experience to find ways to contribute to incremental productivity and develop competitive human capital that is responsive to the needs of the environment and the company.

The evolution of a country can be measured by its capacity for innovation and knowledge of their citizens. $\underline{.4}$ Similarly, for companies also, it is their human capital that distinguishes them from another company. That is why it is important to appreciate that knowledge is an important asset for the company, which is accomplished with training, preparation, and support at the workplace. $\underline{14}^{14}$ The processes of human talent should strengthen the relationship within the company; further, it should be of concern to seek a human orientation based on a measurement of employee performance that focus on results; thus, organisations must constantly prepare, train, and strengthen their collaborators, in aspects of respect, education, interpersonal relationships, teamwork, and change management; if the management does this consistently and achieve repetitive measurements, it can obtain very favourable results for the organisation. $\frac{15}{}$

\subsection{Skills in the Labor Market}

To define the current competencies necessary to perform the work activity, it is important to analyse the requirements of the labour market of today, that is, the skills and competences required to function in a particular role or position within the company. Then we can find authors that expose the concept of competition in the labour market. The labour competence characterises the work environment and behaviour and indicates the level of successful performance on the job. $\underline{16}-\underline{18}$ Labor competence is determined by aspects such as decisionmaking responsibilities, ability of service, employees' attitude in the face of complex situations, academic preparation, and career with the partner contributing to the achievement of the objectives of the company. 19 Actions aimed at labour competencies establish and define what the company wants from the contributor, from the point of view of the competitive performance on the job. Labor competence is a way to measure the behaviour of the collaborator with respect to different situations that arise in the day-to-day functioning, level of empowerment and strengthening of relationships in the work team and their relationships with their superiors. $\underline{20}$ On the other hand, in labour relations in the light of the concept of method based on employee behaviour or skills, $\underline{21}$ it is the individual who can provide the answer whether the needs of the company can be met; each person has specific features, such as physical features; values, skills, and attitudes; desire for professional growth; training in the management of knowledge; and skills for the development of the activities of the organisation.

The skills that must be developed in the organisation are focused on social aspects, such as the relationship with co-workers as well as with citizens and being consistent in their relationship with the workplace and the society. Another skill that is highlighted is with respect to the procedure, which is a method that is explained and written to comply with the working activities without affecting the other processes. Finally, the participatory skills make the partners perceive they are important to the organisation; this is done by involving them more in work activities and business integration processes. Thus, labour skills are key to companies' success and enable companies respond effectively to the needs of the market, society, interest groups, and competitors. $\underline{22}$

In addition, organisations, regardless of size, must be open to change, adapt to trends that exist in the market, and in particular trends in what works in scouting and retaining the best of human talent. With respect to human talent that businesses require, organisations should nurture and train their personnel to sharpen their interpersonal skills, leadership qualities, and decisionmaking and negotiation skills; these are the skills that contributors must develop specific to the company objectives; each job defines what specific skills are required for the performance of the work with results. $\underline{\underline{23}}$

\subsection{Emotional Salary}

Globalisation of economy has brought about changes in work processes, generating massive layoffs, and leading to a decrease of continuity in work tenure in organisations and poor-quality labour conditions. $\underline{24}$ How should these conditions be improved, given the changes in the policies of human talent? From this perspective, the concept of emotional salary, in the quest to improve interpersonal relationships, and strengthen the productivity and competitiveness of the organisations, is needed to be followed to tackle today's competitive global market.

The emotional wage is associated with non-monetary remuneration, which manages to motivate the employee to perform with greater productivity. Loyalty to the organisation is also determined by conditions prevailing in relation to aspects such as employment, interpersonal 
relationships between peers, positive organisational climate, and satisfaction with the activity developed. $\underline{25}$ The management of emotional wage contributes to an organisation's competitiveness, which is based on the motivation of the collaborators and valuing partners looking for a humane and balanced labour activity between family and work ${ }^{1}$. It is important to recognise that labour activity is not only to produce and generate profits in the company but also identify components inherent in the human beings, such as emotions, psychological health, self-realisation, and personal objectives.

The emotional wage pertains to all those non-monetary reasons for which people work and thus a key element for people to feel at ease, committed, and well-aligned in their respective jobs. $\underline{26}$ Salary is an intangible that complements the economic wage, which a collaborator receives in consideration of their labour activity. It is implicit in the concept of basic needs which has a direct impact on individual well-being and on performance and productivity. $\underline{27}$

The emotional salary is any form of compensation, remuneration, non-monetary consideration, which an employee receives in exchange for their labour input. $\underline{28}$ This non-monetary consideration involves considering contributor-specific factors, such as family, hobbies, and emotional and physical state, related to aspects of individual requests for extra labour and considering that each employee is an individual with different needs. $\underline{29}$

These individual needs also have a relationship with emotional intelligence, which shows how to act and reflect on the way to we react to situations reflexively, making our emotions support our behaviour; in addition, it collaborators to take cogent view of their professional and personal decisions. $\frac{30}{}$ At this point, one can conclude that salary is a factor that contributes to the company for its construction of a positive organisational climate reflecting the vision and plan of life of each collaborator within the company; if they are going in the same direction, both parties manage to complement each other in their quest to achieve goals that each of the actors proposes. $\frac{31}{1}$

\subsection{Laboral Satisfaction}

Laboral satisfaction is a globalising concept that refers to the attitudes of people towards various aspects of work. 32 The laboral satisfaction, motivation, and organisational climate make business development an articulated and structured process that seeks to identify factors that can have a positive impact on collaborators, which in turn is reflected in the organisation. $\frac{33}{3}$ The contributor must reflect upon company motivation and satisfaction to fulfil tasks assigned to them efficiently and by means of a positive attitude contribute to developing a positive climate and satisfaction at the time of interacting with other collaborators. A positive organisation aims for a few partners' satisfaction; policies must be created that stimulate a harmonious development and articulate the attitudes, behaviours, and spirit of team work, thereby ensuring that the company is contributing to a better living of its employees. Within this attitude of each individual exists the cognitive part, that is to say, the way an employee sees, feels, and experiences their work and their actions within the company. $\underline{\underline{34}}$

\section{Methodology}

The research focused on the logic of an analytical empirical paradigm according to the object of study proposed and the nature of the approach to the problem. Explanatory research was carried out-not experimental, crosssectional, and deductive. $\frac{35}{}$ The sample was composed of 175 companies in the commercial sector that have between 51 and 200 employees, who were actively earning between US\$1'346.968 and US\$8'081.813 and were located in the city of Medellín. The sample design was stratified probabilistic, the sample had a $95 \%$ reliability and a maximum error of estimate of $7.0 \%$. The hypotheses were:

H1. (Research hypotheses): The strategic, motivational, human, and value creation dimensions explain the construction of an emotional salary model consistent with the logic of the strategic management of human talent, humanised management, and modern enterprise.

H0. (Null hypotheses): The strategic, motivational, human, and value creation dimensions do not explain the construction of an emotional salary model consistent with the logic of the strategic management of human talent, humanised management, and modern business.

Considering a finite population, the size of the sample was determined using the following formula:

\subsection{Variables and Dimensions}

The instrument structure is composed of a set of items presented in the form of statements with a Likert scale (1-5) shown in Table 1: 
Table 1. Likert scale

\begin{tabular}{|l|c|}
\hline Statement & Level \\
\hline Totally agree & 5 \\
\hline Agree & 4 \\
\hline Partially of agreement & 3 \\
\hline In disagreement & 2 \\
\hline Strongly disagree & 1 \\
\hline
\end{tabular}

The following is a description of each dimension and the proposed items.

\subsubsection{Strategic Dimension}

The study focuses on identifying how by using strategic planning items can be set that help design the model of emotional salary. It contributes in a wide range, from the direction of the organisation to the construction of a healthy and motivated company and includes the following items: organisational culture, leadership and management support, flexible organisational structure, resources and organisational capacities, style of leadership and direction of management, management of human talent, working conditions, and organisational climate.

\subsubsection{Motivational Dimension}

The contributors are the strategic asset of the organisation, which is why they must remain motivated to respond satisfactorily to the organisation's external environment and customer requirements. It is the motivation to work, together with other elements that make a contributor to perceive that it is important for the company, includes the following items: working conditions, labour surveys, self-improvement, personal growth, professional growth, remuneration policy, scale of acknowledgments, labour flexibility, and laboral happiness.

\subsubsection{Human Dimension}

Determined by the conditions that allow you to achieve the results and generate a competitive advantage, departing from the team of collaborators, it includes the following items: self-realisation, opportunity of promotion, training opportunities, commitment to organisation, personal attitude, loyalty to co-workers, family time, respect for diversity, and healthy living.

\subsubsection{Creation of Value Dimension}

The management of the value relates to the design and implementation of a strategy that integrates the business processes to better utilise available resources (capital) in such a way that results generated (measured not only in financial performance but also in satisfaction of customers, employees, and the community in general) are higher than expected by investors and includes the following items: economic bonuses, allowances and bonuses, retention plan for best collaborators, budget for training, recognition, management by objectives to retain customers through actions of collaborators, planning of health policies, and compensation to partners according to results and creation of value.

\section{Results}

The following are the results found after the application of the test defined for the construction of a model of emotional salary. In the first place, we proceeded to validation by experts, in order to design a test to measure and collect information that is relevant and appropriate. The expert panel was comprised of eleven teachers, researchers, and professionals with experience in research projects in different disciplines, which contributed to the interdisciplinarity of the study; the objective was to determine whether the proposed items have a relationship with the design of the model of emotional salary; we reviewed 47 items, which are valued by means of a Likert scale, where 1 = strongly agree, 2 = agree, $3=$ somewhat agree, $4=$ disagree, and $5=$ strongly disagree; the main purpose of the validation of the instrument was that it complied with the criteria of reliability, objectivity, and validity for later application.

Once the instrument was validated, the experts proceeded with the purification of the test, which resulted in the reduction of number of items from 47 to 34 items, and their subsequent application; the application of test was carried out in companies according to the characterisation of the sample proposal, which in this case were 176 companies that belong to the segment of medium-sized enterprises according to number of employees and assets and all were located geographically in the city of Medellín. Subsequent to the application of the test, and in the consolidation of the responses on the part of each one of the units of study, we proceeded to complete the database with all the information and then commenced data processing using SPPS software, version 24 and generated different statistical details. The following explains in a general way about each of the explanatory 
indexes, and then in a detailed manner, the tables, figures, and tables presented here explain the study's findings.

The first part of the analysis of the results is made up of the characterisation of each of the dimensions proposed, that is, strategic dimension, human management, motivational factors, and value creation; for this, we defined a matrix that allowed us to prove the equivalence between the scores and the standard scores obtained in the validation process. The second analysis was carried out on the basis of the scales of each of the dimensions, as well as the strategic dimension, and it presented a standard score in a range of 1 to 5 , and for the human dimension the standard score was for a range of 1 to 3.33; the dimension of value creation is defined with a standard score in the range of 3.86 to 1 , and for the motivational dimension the standard score for symptoms absent was in the range of 1 to 4 .

The reliability of the test was developed from an analysis of statistical reliability through the Cronbach's alpha; this was applied to the number of items in general, then based on the results obtained in the analysis of reliability, it was determined that it is clear that the instrument with which it is evaluating the sample is appropriate to that effect, taking into account the statistical significance that was arrived at: 0.941 . Then we proceeded to use Cronbach's alpha to determine the internal consistency of the items; we correlated each of the items that were used in the test and again applied the Cronbach's alpha.

The following analysis shows the variance between factors; it is noted these are mutually exclusive, as their significance is less than 0.00 , and in relation to the overall scale of measurement, the Cronbach's alpha statistic was 0.854. In addition, a factor analysis was performed to determine the number and the nature of the group of constructs that are underlying as a set of independent variables that affect the dependent variable; for this purpose, we used the statistical value of Kaiser-MeyerOlkin (KMO) and Bartlett's Chi-square test; the null hypothesis revealed that the correlation matrix was not different from the identity matrix, and the alternative hypothesis showed that the correlation matrix differed significantly from the identity matrix.

Then we analysed the explained variance, with the cloud of points adjusted to a perfect sphere, and this statistic was greater than 0.65 ; it can be said that the factorial analysis procedure applied is optimal in this case. Also, the results are analysed on the basis of the factor loading obtained for each component after rotation. For the first component items were grouped that determined the motivational load from the management; the second group of items refer to the strategic factors of the organisation; the third group of items refer to the human component, factors such as personal growth within companies; and the fourth and last refer to the composition of the items concerning the dimension of value creation in the enterprise or on the job.

Then, the results are determined with respect to the characterisation of each dimension, the questions that are involved in the strategic dimension are focused on processes of addressing, and all answers are mostly of people who responded affirmatively ( 1 and 2), representing about $92 \%$ of the answers, with a slight dispersion between answers. The results of the human dimension are focused on processes of opportunities for advancement of collaborators, where all the answers were mostly from people who responded affirmatively ( 1 and 2 ), representing about $92 \%$ of answers, but with a slight deviation between the responses obtained. As to the questions that involved the dimension of value creation, which are focused on business situations and relationship with the client, most of the respondents answered affirmatively ( 1 and 2), about $90 \%$, and there was minimum dispersion between the responses obtained. About the motivational dimension, it was noted that the questions involving this dimension extracted affirmative answers mostly (1 and 2), about $85 \%$, and there was greater dispersion among the answers.

Finally, the last two analyses are the Kappa index, which relates the agreement that the observers exhibited, beyond the due chance, with the potential agreement, which was also beyond the random. The process of development of the index calculated the difference between the proportion, according to what has been observed, and the proportion of agreement expected by chance. $\frac{36}{}$ At the same time, symmetric measures that measure the statistical methods for the evaluation of the consistency and reproducibility are dependent on the characteristics of the phenomenon to study and should be subject to a rigorous methodology and be specific. Our selection depended on the variable type to be measured and the parameters we wanted to evaluate. Table 2 presents the characterisation of the dimensions or components:

Then, there was an array of equivalence between the scores and the standard scores obtained in the validation process for each of the variables and the global scale, showing the values with which it will be possible to compare the scores with populations similar to the study. Typical scores used for the standardisation of the 
Table 2. Characterisation

\begin{tabular}{|c|c|c|c|c|c|}
\hline & & Strategic & Human & $\begin{array}{l}\text { Creation } \\
\text { of value }\end{array}$ & Motivational \\
\hline \multicolumn{2}{|l|}{ Average } & 1.4590 & 1.3371 & 1.3839 & 1.5499 \\
\hline \multicolumn{2}{|l|}{ Mode } & 1.00 & 1.00 & 1.00 & 1.00 \\
\hline \multicolumn{2}{|l|}{$\begin{array}{l}\text { Standard } \\
\text { deviation }\end{array}$} & .48990 & .40104 & .47489 & .53693 \\
\hline \multicolumn{2}{|l|}{ Range } & 3.56 & 2.33 & 2.86 & 3.00 \\
\hline \multicolumn{2}{|l|}{ Mín } & 1.00 & 1.00 & 1.00 & 1.00 \\
\hline \multicolumn{2}{|l|}{ Máx } & 4.56 & 3.33 & 3.86 & 4.00 \\
\hline \multicolumn{2}{|l|}{ Sum } & 256.78 & 235.33 & 243.57 & 272.78 \\
\hline \multirow{3}{*}{ Percentiles } & 25 & 1.0000 & 1.0000 & 1.0000 & 1.0000 \\
\hline & 50 & 1.3333 & 1.2222 & 1.2857 & 1.4444 \\
\hline & 75 & 1.7778 & 1.5556 & 1.5714 & 1.8889 \\
\hline
\end{tabular}

instrument are 1 and 2, which correspond to the ranges of standard scores obtained in relation to each of the deviations of the variables evaluated.

For the studied population is that the strategic dimension, presents a standard score in a range of 1 to 5 , and for the human presents a standard score in a range of 1 to 3.33; the creation of value is set with a standard score in a range of 1 to 3.86; and for the motivational presents a standard score for symptoms absent in a range of 1 to 4 . The target population, under a normal curve is defined as a structure of approximate values for the factors or each of the components that are defined on the basis of the following measures. Table 3, presents the main descriptive statistics:

On the other hand, it uses the method of internal consistency based on the Cronbach's alpha test (1951), which allows us to estimate the reliability of a measurement instrument through a set of items, based on the quantification of the correlation that exists between the items that comprise it. The measure of the reliability using Cronbach's alpha assumes that the items (measured on a Likert-type scale) measure the same construct and are highly correlated.

\subsection{Analysis of Reliability Results}

For the analysis of reliability of the test, we used the Cronbach's alpha statistic, which was applied to the number of items in general and, in addition, the
Table 3. Baremos for the components

\begin{tabular}{|l|l|l|l|l|}
\hline & Average & $\begin{array}{l}\text { Standard } \\
\text { deviation }\end{array}$ & Mín & Máx \\
\hline Strategic & 1.4590 & .48990 & 1.00 & 4.56 \\
\hline Human & 1.3371 & .40104 & 1.00 & 3.33 \\
\hline $\begin{array}{l}\text { Creation of } \\
\text { value }\end{array}$ & 1.3839 & .47489 & 1.00 & 3.86 \\
\hline Motivational & 1.5499 & .53693 & 1.00 & 4.00 \\
\hline
\end{tabular}

Table 4. Statistical reliability

\begin{tabular}{|l|l|}
\hline Cronbach's alpha & Number of elements \\
\hline .941 & 34 \\
\hline
\end{tabular}

number of elements. Based on the results obtained in the analysis of reliability, it is clear that the instrument used for evaluating the sample was appropriate, taking into account the statistical significance at 0.941 . Table 4 presents the Cronbach's alpha.

To determine the consistency of items their correlation of each of the elements was studied and the Cronbach's alpha coefficient was again applied to the study results. Table 5 presents the Cronbach's alpha statistic for items deleted:

If you look at every one of the items above, it is evident that there is no greater difference between each score of the construct and that the values obtained are significant statistically. However, taking into account the analysis of variance between the factors, it is noted that based on the instrument applied the factors were mutually exclusive, as the significance was less than 0.00 ; and in relation to the overall scale of measurement, the Cronbach's alpha was 0.854 , which indicates a level of reliability for each one of the variables and the global scale, establishing a high level of confidence for the measurement of an emotional wage model in similar populations; the values in each of the dimensions are: strategic dimension, with an alpha of 0.830 ; human dimension, with an alpha of 0.779 ; the creation of value, with a rating of 0.774 ; and the motivational speaker, with an alpha of 0.789 . Table 6 presents the variance analysis:

The independence between the items is intervened by the prior verification of the assumptions to assess how big can be the estimation bias, since they are calculated by the effect of the correlation between the errors of the alpha. At the same time, contrast is generated on the assumption that there is a multiplicative interaction between the 
Table 5. Cronbach's alpha statistic

\begin{tabular}{|c|c|c|c|c|}
\hline & Average & Variance & $\begin{array}{c}\text { Total correlation } \\
\text { of items }\end{array}$ & Cronbach's alpha \\
\hline P1 Style of organisational culture & 47.28 & 168.102 & .452 & .940 \\
\hline P2 Leadership and management support & 47.35 & 168.961 & .459 & .940 \\
\hline P3 Flexible organisational structure & 47.16 & 166.287 & .530 & .940 \\
\hline P4 Organisational resources and capacities & 47.26 & 165.734 & .613 & .939 \\
\hline P5 Style of leadership and management & 47.32 & 166.895 & .538 & .939 \\
\hline P6 Management of the area of human talent & 47.34 & 166.750 & .533 & .939 \\
\hline P7 Working conditions & 47.38 & 167.687 & .496 & .940 \\
\hline P8 Organisational climate & 47.45 & 166.329 & .610 & .939 \\
\hline P9 Working conditions & 47.53 & 169.987 & .511 & .940 \\
\hline P10 Self-improvement & 47.34 & 167.698 & .527 & .940 \\
\hline P11 Labor surveys & 47.41 & 167.729 & .567 & .939 \\
\hline P12 Professional growth & 47.53 & 169.176 & .573 & .939 \\
\hline P13 Personal growth & 47.53 & 168.970 & .603 & .939 \\
\hline P14 Remuneration policy & 47.34 & 166.910 & .544 & .939 \\
\hline P15 Scale of acknowledgments & 47.30 & 165.318 & .620 & .939 \\
\hline P16 Labor flexibility & 47.34 & 167.106 & .520 & .940 \\
\hline P17 Labor happiness & 47.48 & 166.834 & .604 & .939 \\
\hline P18 Self-realisation & 47.47 & 167.919 & .610 & .939 \\
\hline P19 Opportunity of promotion & 47.44 & 166.877 & .591 & .939 \\
\hline P20 Training opportunities & 47.50 & 169.154 & .546 & .939 \\
\hline P21 Commitment to the organisation & 47.38 & 168.763 & .497 & .940 \\
\hline P22 Personal attitude & 47.53 & 168.925 & .567 & .939 \\
\hline P23 Policy of loyalty to the collaborators & 47.28 & 165.370 & .609 & .939 \\
\hline P24 Time for the family & 47.58 & 170.542 & .459 & .940 \\
\hline P25 Respect for diversity & 47.44 & 167.265 & .567 & .939 \\
\hline P26 Healthy living & 47.38 & 165.174 & .649 & .938 \\
\hline P27 Bonificaciones económicas & 47.14 & 162.496 & .613 & .939 \\
\hline P28 Compensation and bonuses & 47.16 & 163.144 & .604 & .939 \\
\hline P29 Retention plan of best collaborators & 47.30 & 166.497 & .553 & .939 \\
\hline P30 Budget for training & 47.45 & 169.369 & .494 & .940 \\
\hline P31 Recognition by objectives & 47.40 & 166.321 & .592 & .939 \\
\hline $\begin{array}{l}\text { P32 Management to retain customers through } \\
\text { the actions of the collaborators }\end{array}$ & 47.15 & 165.658 & .531 & .940 \\
\hline P33 Plan of health policies & 47.18 & 166.683 & .508 & .940 \\
\hline $\begin{array}{l}\text { P34 Compensation to the partners according } \\
\text { to the results with the creation of value }\end{array}$ & 47.31 & 166.568 & .506 & .940 \\
\hline
\end{tabular}

elements; the responses of each treatment group are the sum of the overall average coupled to a random effect that is associated with the general response. In this way, and taking into account the value of statistical significance, it can be concluded that the elements set approve the hypothesis that effects are not additive. In addition, a factor analysis was performed to determine the number and the nature of the group of constructs that are underlying as 
Table 6. Variance results

\begin{tabular}{|c|c|c|c|c|c|c|c|}
\hline & & & Squares sum & Gl & Mean square & $\mathbf{F}$ & Sig. \\
\hline \multicolumn{3}{|l|}{ Inter-subject } & 136.787 & 175 & .782 & & \\
\hline \multirow{5}{*}{ Intra-subject } & \multicolumn{2}{|c|}{ Between Elements } & 6.325 & 4 & 1.581 & 13.851 & .000 \\
\hline & \multirow{3}{*}{ Remainder } & Non-additivity & $1.054 \mathrm{a}$ & 1 & 1.054 & 9.339 & .002 \\
\hline & & Balance & 78.859 & 699 & .113 & & \\
\hline & & Total & 79.913 & 700 & .114 & & \\
\hline & \multicolumn{2}{|l|}{ Total } & 86.238 & 704 & .122 & & \\
\hline \multicolumn{3}{|l|}{ Total } & 223.025 & 879 & .254 & & \\
\hline \multicolumn{8}{|c|}{ Global average $=1.4347$} \\
\hline
\end{tabular}

Table 7. KMO statistic

\begin{tabular}{|l|l|l|}
\hline Kaiser-Meyer-Olkin & .874 \\
\hline \multirow{3}{*}{ Bartlett Sphericity Test } & Aprox Chi-cuadrado & 3526.743 \\
\cline { 2 - 3 } & Gl & 561 \\
\cline { 2 - 3 } & Sig. & 0.000 \\
\hline
\end{tabular}

a set of independent variables that affect the dependent variable. Table 7 presents the sphericity results:

Taking as a basis the statistical value of KMO and Bartlett, which is based on the Chi-square test, the null hypothesis says that the correlation matrix is not going to differentiate it from the identity matrix, and the alternative hypothesis says that the correlation matrix will differ significantly from the identity matrix; the cloud of points is adjusted to a perfect sphere, and this statistic, higher than 0.65 , can show that the factorial analysis procedure applied was optimal in this case. Table 8 presents the explained variance:

Continuing with the process is a varimax rotation; this method maximises the variance of factors. On the other hand, the proportion of variability of each variable explained by the factors or is the sum of the weights factor to the square in each row and each column of the matrix where rotated factorial loads will be high with some variables, and low with others, which facilitated the interpretation. Table 9 presents the factor loading obtained for each component after rotation:

From the factor loading obtained for the interpretation of each component, it was observed that for the first of them are grouped items that determine the motivational load from the management; the second group of items refer to the strategic factors from the organisation; the third, for its part, brings together items that refer to the human component, such as factors for personal growth within organisations; and the fourth and last refer to the composition of items concerning the dimension of value creation in the enterprise or on the job. The values that determine whether the variables are distributed or not normally endorse the alternative hypothesisthat variables do not come from a normal distribution. So it is appropriate to establish a non-parametric analysis to interpret the results. However, for each of the dimensions, the ratings obtained, according to the characterisation of the answers, were the following. Table 10 presents the characterisation of the strategic dimension:

It is noted that the questions in this dimension are focused on processes of addressing, and all answers are routed, the vast majority of people who respond positively ( 1 and 2 ), representing about a $92 \%$, with a slight dispersion among the answers. Table 11, presents the characterisation of the human dimension:

According to the above results, the questions of this dimension are focused on processes of development opportunities of employees, where all the answers are routed, and the vast majority of people =responded positively ( 1 and 2 , representing about a $92 \%$ ); there was a slight deviation between the responses obtained. Table 12 presents the characterisation of the value creation dimension:

The questions involving this dimension correspond to processes of loyalty in the business field, and the vast majority of people responded positively (1 and 2, representing about a 94\%); there was a slight dispersion among the answers. Table 13 presents the characterisation of the motivational dimension:

On the other hand, it is noted that the questions involving this dimension are focused mostly on people who responded affirmatively ( 1 and 2 , representing about 
Table 8. Variance analysis

\begin{tabular}{|c|c|c|c|c|c|c|c|c|c|}
\hline \multirow{2}{*}{$\begin{array}{l}\text { Com- } \\
\text { ponent }\end{array}$} & \multicolumn{3}{|c|}{ Initial eigenvalues } & \multicolumn{3}{|c|}{$\begin{array}{l}\text { Sums of removal of loads to the } \\
\text { square }\end{array}$} & \multicolumn{3}{|c|}{$\begin{array}{c}\text { Amounts of rotation of loads to the } \\
\text { square }\end{array}$} \\
\hline & Total & $\%$ variance & $\begin{array}{l}\% \text { accumu- } \\
\text { lated }\end{array}$ & Total & $\%$ variance & $\begin{array}{l}\% \text { accumu- } \\
\text { lated }\end{array}$ & Total & $\%$ variance & $\begin{array}{l}\% \text { accumu- } \\
\text { lated }\end{array}$ \\
\hline 1 & 11.832 & 34.800 & 34.800 & 11.832 & 34.800 & 34.800 & 4.755 & 13.984 & 13.984 \\
\hline 2 & 2.736 & 8.046 & 42.846 & 2.736 & 8.046 & 42.846 & 4.722 & 13.889 & 27.873 \\
\hline 3 & 2.078 & 6.112 & 48.959 & 2.078 & 6.112 & 48.959 & 4.649 & 13.672 & 41.545 \\
\hline 4 & 1.620 & 4.764 & 53.723 & 1.620 & 4.764 & 53.723 & 4.140 & 12.178 & 53.723 \\
\hline 5 & 1.353 & 3.979 & 57.702 & & & & & & \\
\hline 6 & 1.252 & 3.681 & 61.383 & & & & & & \\
\hline 7 & 1.142 & 3.359 & 64.742 & & & & & & \\
\hline 8 & 1.067 & 3.137 & 67.880 & & & & & & \\
\hline 9 & .977 & 2.874 & 70.754 & & & & & & \\
\hline 10 & .839 & 2.467 & 73.221 & & & & & & \\
\hline 11 & .763 & 2.243 & 75.463 & & & & & & \\
\hline 12 & .712 & 2.096 & 77.559 & & & & & & \\
\hline 13 & .665 & 1.957 & 79.516 & & & & & & \\
\hline 14 & .604 & 1.775 & 81.291 & & & & & & \\
\hline 15 & .583 & 1.715 & 83.006 & & & & & & \\
\hline 16 & .550 & 1.618 & 84.623 & & & & & & \\
\hline 17 & .516 & 1.519 & 86.142 & & & & & & \\
\hline 18 & .491 & 1.443 & 87.585 & & & & & & \\
\hline 19 & .449 & 1.319 & 88.905 & & & & & & \\
\hline 20 & .422 & 1.240 & 90.145 & & & & & & \\
\hline 21 & .401 & 1.180 & 91.325 & & & & & & \\
\hline 22 & .341 & 1.002 & 92.326 & & & & & & \\
\hline 23 & .336 & .987 & 93.314 & & & & & & \\
\hline 24 & .298 & .876 & 94.190 & & & & & & \\
\hline 25 & .284 & .834 & 95.024 & & & & & & \\
\hline 26 & .266 & .782 & 95.806 & & & & & & \\
\hline 27 & .258 & .759 & 96.565 & & & & & & \\
\hline 28 & .237 & .697 & 97.261 & & & & & & \\
\hline 29 & .211 & .621 & 97.882 & & & & & & \\
\hline 30 & .199 & .586 & 98.469 & & & & & & \\
\hline 31 & .175 & .514 & 98.982 & & & & & & \\
\hline 32 & .150 & .443 & 99.425 & & & & & & \\
\hline 33 & .119 & .349 & 99.774 & & & & & & \\
\hline 34 & .077 & .226 & 100.000 & & & & & & \\
\hline
\end{tabular}

Extraction method: analysis of main components.

a 85\%); there was a dispersion between the answers. In accordance with the sample size, the confidence level, and the margin of error referred to, it is considered that the findings of the study are discriminating, with respect to the references found for the middle; moreover, taking into account the results, we suggest using experts to conduct follow-up investigations among the study population. Table 14 presents the Mann-Whitney $U$ Test results:

It can be concluded that the differences by group of statistical measurements at different times of the survey were not statistically significant enough to determine 
Table 9. Factor loading

\begin{tabular}{|c|c|c|c|c|}
\hline & Motivational & Strategic & Human & Creation of value \\
\hline P28 Compensation and bonuses & .732 & & & \\
\hline P27 Economic bonuses & .712 & & & \\
\hline $\begin{array}{l}\text { P34 Compensation to the partners according to } \\
\text { the results and the creation of value }\end{array}$ & .707 & & & \\
\hline P29 Retention plan of best collaborators & .654 & & & \\
\hline P15 Scale of acknowledgments & .624 & & & \\
\hline $\begin{array}{l}\text { P32 Management to retain customers through } \\
\text { the actions of collaborators }\end{array}$ & .591 & & & \\
\hline P33 Plan of health policies & .582 & & & \\
\hline P31 Recognition by objectives & .515 & & & \\
\hline P14 Remuneration policy & .491 & & & \\
\hline P5 Style of leadership and management & & .755 & & \\
\hline P2 Leadership and management support & & .750 & & \\
\hline P1 Style of organisational culture & & .732 & & \\
\hline P8 Organisational climate & & .724 & & \\
\hline P7 Working conditions & & .702 & & \\
\hline P4 Organisational resources and capacities & & .696 & & \\
\hline P6 Management of the area of human talent & & .617 & & \\
\hline P3 Flexible organisational structure & & .567 & & \\
\hline P9 Working conditions & & .378 & & \\
\hline P22 Personal attitude & & & .703 & \\
\hline P13 Personal growth & & & .684 & \\
\hline P12 Professional growth & & & .674 & \\
\hline P18 Self-realisation & & & .618 & \\
\hline P21 Commitment to the organisation & & & .616 & \\
\hline P20 Training opportunities & & & .609 & \\
\hline P10 Self-improvement & & & .576 & \\
\hline P30 Budget for training & & & .525 & \\
\hline P19 Opportunity of promotion & & & .428 & \\
\hline P25 Respect for diversity & & & & .680 \\
\hline P11 Labor surveys & & & & .642 \\
\hline P24 Time for the family & & & & .627 \\
\hline P26 Healthy living & & & & .617 \\
\hline P23 Policy of loyalty to the collaborators & & & & .596 \\
\hline P17 Labor happiness & & & & .574 \\
\hline P16 Labor flexibility & & & & .564 \\
\hline
\end{tabular}


Table 10. Characterisation SD

\begin{tabular}{|c|c|c|c|}
\hline & & Recount & $\begin{array}{c}\% \text { Number of } \\
\text { columns }\end{array}$ \\
\hline \multirow{6}{*}{$\begin{array}{l}\text { P1 Style of } \\
\text { organisational } \\
\text { culture }\end{array}$} & 1 & 102 & $57.95 \%$ \\
\hline & 2 & 62 & $35.23 \%$ \\
\hline & 3 & 9 & $5.11 \%$ \\
\hline & 4 & 1 & $0.57 \%$ \\
\hline & 5 & 2 & $1.14 \%$ \\
\hline & Total & 176 & $100.00 \%$ \\
\hline \multirow{5}{*}{$\begin{array}{l}\text { P2 Leadership and } \\
\text { management support }\end{array}$} & 1 & 109 & $61.93 \%$ \\
\hline & 2 & 57 & $32.39 \%$ \\
\hline & 3 & 9 & $5.11 \%$ \\
\hline & 5 & 1 & $0.57 \%$ \\
\hline & Total & 176 & $100.00 \%$ \\
\hline \multirow{6}{*}{$\begin{array}{l}\text { P3 Flexible } \\
\text { organisational } \\
\text { structure }\end{array}$} & 1 & 89 & $50.57 \%$ \\
\hline & 2 & 65 & $36.93 \%$ \\
\hline & 3 & 20 & $11.36 \%$ \\
\hline & 4 & 1 & $0.57 \%$ \\
\hline & 5 & 1 & $0.57 \%$ \\
\hline & Total & 176 & $100.00 \%$ \\
\hline \multirow{6}{*}{$\begin{array}{l}\text { P4 Organisational } \\
\text { resources and } \\
\text { capacities }\end{array}$} & 1 & 96 & $54.55 \%$ \\
\hline & 2 & 67 & $38.07 \%$ \\
\hline & 3 & 11 & $6.25 \%$ \\
\hline & 4 & 1 & $0.57 \%$ \\
\hline & 5 & 1 & $0.57 \%$ \\
\hline & Total & 176 & $100.00 \%$ \\
\hline \multirow{5}{*}{$\begin{array}{l}\text { P5 Style of leadership } \\
\text { and management }\end{array}$} & 1 & 110 & $62.50 \%$ \\
\hline & 2 & 50 & $28.41 \%$ \\
\hline & 3 & 15 & $8.52 \%$ \\
\hline & 5 & 1 & $0.57 \%$ \\
\hline & Total & 176 & $100.00 \%$ \\
\hline \multirow{6}{*}{$\begin{array}{l}\text { P6 Management of } \\
\text { the area of human } \\
\text { talent }\end{array}$} & 1 & 113 & $64.20 \%$ \\
\hline & 2 & 47 & $26.70 \%$ \\
\hline & 3 & 14 & $7.95 \%$ \\
\hline & 4 & 1 & $0.57 \%$ \\
\hline & 5 & 1 & $0.57 \%$ \\
\hline & Total & 176 & $100.00 \%$ \\
\hline \multirow{6}{*}{$\begin{array}{l}\text { P7 Working } \\
\text { conditions }\end{array}$} & 1 & 116 & $65.91 \%$ \\
\hline & 2 & 50 & $28.41 \%$ \\
\hline & 3 & 6 & $3.41 \%$ \\
\hline & 4 & 3 & $1.70 \%$ \\
\hline & 5 & 1 & $0.57 \%$ \\
\hline & Total & 176 & $100.00 \%$ \\
\hline \multirow{6}{*}{$\begin{array}{l}\text { P8 Organisational } \\
\text { climate }\end{array}$} & 1 & 129 & $73.30 \%$ \\
\hline & 2 & 36 & $20.45 \%$ \\
\hline & 3 & 9 & $5.11 \%$ \\
\hline & 4 & 1 & $0.57 \%$ \\
\hline & 5 & 1 & $0.57 \%$ \\
\hline & Total & 176 & $100.00 \%$ \\
\hline \multirow{4}{*}{$\begin{array}{l}\text { P9 Working } \\
\text { conditions }\end{array}$} & 1 & 135 & $76.70 \%$ \\
\hline & 2 & 35 & $19.89 \%$ \\
\hline & 3 & 6 & $3.41 \%$ \\
\hline & Total & 176 & $100.00 \%$ \\
\hline \multicolumn{4}{|l|}{ Strategic } \\
\hline \multicolumn{4}{|l|}{ Average 1.46} \\
\hline \multicolumn{4}{|l|}{ Standard deviation 0.49} \\
\hline
\end{tabular}

Table 11. Characterisation HD

\begin{tabular}{|c|c|c|c|}
\hline & & Recount & $\begin{array}{l}\text { \% Number } \\
\text { of columns }\end{array}$ \\
\hline \multirow{5}{*}{ P10 Self-improvement } & 1 & 109 & $61.93 \%$ \\
\hline & 2 & 53 & $30.11 \%$ \\
\hline & 3 & 13 & $7.39 \%$ \\
\hline & 4 & 1 & $0.57 \%$ \\
\hline & Total & 176 & $100.00 \%$ \\
\hline \multirow{5}{*}{ P12 Professional growth } & 1 & 134 & $76.14 \%$ \\
\hline & 2 & 38 & $21.59 \%$ \\
\hline & 3 & 3 & $1.70 \%$ \\
\hline & 4 & 1 & $0.57 \%$ \\
\hline & Total & 176 & $100.00 \%$ \\
\hline \multirow{5}{*}{ P13 Personal growth } & 1 & 133 & $75.57 \%$ \\
\hline & 2 & 40 & $22.73 \%$ \\
\hline & 3 & 2 & $1.14 \%$ \\
\hline & 4 & 1 & $0.57 \%$ \\
\hline & Total & 176 & $100.00 \%$ \\
\hline \multirow{5}{*}{ P18 Self-realisation } & 1 & 124 & $70.45 \%$ \\
\hline & 2 & 46 & $26.14 \%$ \\
\hline & 3 & 5 & $2.84 \%$ \\
\hline & 4 & 1 & $0.57 \%$ \\
\hline & Total & 176 & $100.00 \%$ \\
\hline \multirow{5}{*}{$\begin{array}{l}\text { P19 Opportunity of } \\
\text { promotion }\end{array}$} & 1 & 126 & $71.59 \%$ \\
\hline & 2 & 40 & $22.73 \%$ \\
\hline & 3 & 7 & $3.98 \%$ \\
\hline & 4 & 3 & $1.70 \%$ \\
\hline & Total & 176 & $100.00 \%$ \\
\hline \multirow{4}{*}{ P20 Training opportunities } & 1 & 130 & $73.86 \%$ \\
\hline & 2 & 39 & $22.16 \%$ \\
\hline & 3 & 7 & $3.98 \%$ \\
\hline & Total & 176 & $100.00 \%$ \\
\hline \multirow{4}{*}{$\begin{array}{l}\text { P21 Commitment to the } \\
\text { organisation }\end{array}$} & 1 & 114 & $64.77 \%$ \\
\hline & 2 & 50 & $28.41 \%$ \\
\hline & 3 & 12 & $6.82 \%$ \\
\hline & Total & 176 & $100.00 \%$ \\
\hline \multirow{5}{*}{ P22 Personal attitude } & 1 & 136 & $77.27 \%$ \\
\hline & 2 & 34 & $19.32 \%$ \\
\hline & 3 & 5 & $2.84 \%$ \\
\hline & 4 & 1 & $0.57 \%$ \\
\hline & Total & 176 & $100.00 \%$ \\
\hline \multirow{4}{*}{ P30 Budget for training } & 1 & 123 & $69.89 \%$ \\
\hline & 2 & 44 & $25.00 \%$ \\
\hline & 3 & 9 & $5.11 \%$ \\
\hline & Total & 176 & $100.00 \%$ \\
\hline \multicolumn{4}{|l|}{ Human } \\
\hline \multicolumn{4}{|l|}{ Average 1.34} \\
\hline \multicolumn{4}{|l|}{ Standard deviation 0.40} \\
\hline
\end{tabular}


Table 12. Characterisation VCD

\begin{tabular}{|c|c|c|c|}
\hline & & Recount & $\begin{array}{l}\% \text { Number of } \\
\text { columns }\end{array}$ \\
\hline \multirow{5}{*}{ P11 Labor surveys } & 1 & 118 & $67.05 \%$ \\
\hline & 2 & 48 & $27.27 \%$ \\
\hline & 3 & 9 & $5.11 \%$ \\
\hline & 4 & 1 & $0.57 \%$ \\
\hline & Total & 176 & $100.00 \%$ \\
\hline \multirow{5}{*}{ P16 Labor flexibility } & 1 & 114 & $64.77 \%$ \\
\hline & 2 & 46 & $26.14 \%$ \\
\hline & 3 & 13 & $7.39 \%$ \\
\hline & 4 & 3 & $1.70 \%$ \\
\hline & Total & 176 & $100.00 \%$ \\
\hline \multirow{5}{*}{ P17 Labor happiness } & 1 & 132 & $75.00 \%$ \\
\hline & 2 & 36 & $20.45 \%$ \\
\hline & 3 & 4 & $2.27 \%$ \\
\hline & 4 & 4 & $2.27 \%$ \\
\hline & Total & 176 & $100.00 \%$ \\
\hline \multirow{5}{*}{$\begin{array}{l}\text { P23 Policy for loyalty } \\
\text { to the collaborators }\end{array}$} & 1 & 106 & $60.23 \%$ \\
\hline & 2 & 51 & $28.98 \%$ \\
\hline & 3 & 17 & $9.66 \%$ \\
\hline & 4 & 2 & $1.14 \%$ \\
\hline & Total & 176 & $100.00 \%$ \\
\hline \multirow{5}{*}{$\begin{array}{l}\text { P24 Time for the } \\
\text { family }\end{array}$} & 1 & 144 & $81.82 \%$ \\
\hline & 2 & 27 & $15.34 \%$ \\
\hline & 3 & 3 & $1.70 \%$ \\
\hline & 4 & 2 & $1.14 \%$ \\
\hline & Total & 176 & $100.00 \%$ \\
\hline \multirow{5}{*}{$\begin{array}{l}\text { P25 Respect for } \\
\text { diversity }\end{array}$} & 1 & 126 & $71.59 \%$ \\
\hline & 2 & 40 & $22.73 \%$ \\
\hline & 3 & 7 & $3.98 \%$ \\
\hline & 4 & 3 & $1.70 \%$ \\
\hline & Total & 176 & $100.00 \%$ \\
\hline \multirow{5}{*}{ P26 Healthy living } & 1 & 118 & $67.05 \%$ \\
\hline & 2 & 46 & $26.14 \%$ \\
\hline & 3 & 8 & $4.55 \%$ \\
\hline & 4 & 4 & $2.27 \%$ \\
\hline & Total & 176 & $100.00 \%$ \\
\hline \multicolumn{4}{|l|}{ Creation of value } \\
\hline \multicolumn{4}{|l|}{ Average 1.38} \\
\hline \multicolumn{4}{|l|}{ Standard deviation 0.47} \\
\hline
\end{tabular}

Table 13. Characterisation MD

\begin{tabular}{|c|c|c|c|}
\hline & & Recount & $\begin{array}{c}\% \mathrm{~N} \\
\text { columns }\end{array}$ \\
\hline & 1 & 113 & $64.20 \%$ \\
\hline & 2 & 45 & $25.57 \%$ \\
\hline P14 Remuneration policy & 3 & 17 & $9.66 \%$ \\
\hline & 4 & 1 & $0.57 \%$ \\
\hline & Total & 176 & $100.00 \%$ \\
\hline & 1 & 108 & $61.36 \%$ \\
\hline & 2 & 48 & $27.27 \%$ \\
\hline PIS scale of & 3 & 19 & $10.80 \%$ \\
\hline & 4 & 1 & $0.57 \%$ \\
\hline & Total & 176 & $100.00 \%$ \\
\hline & 1 & 95 & $53.98 \%$ \\
\hline & 2 & 55 & $31.25 \%$ \\
\hline D27 Economic honuco & 3 & 19 & $10.80 \%$ \\
\hline P2/ Economic Donuses & 4 & 4 & $2.27 \%$ \\
\hline & 5 & 3 & $1.70 \%$ \\
\hline & Total & 176 & $100.00 \%$ \\
\hline & 1 & 99 & $56.25 \%$ \\
\hline & 2 & 49 & $27.84 \%$ \\
\hline P28 Compensation and & 3 & 23 & $13.07 \%$ \\
\hline bonuses & 4 & 3 & $1.70 \%$ \\
\hline & 5 & 2 & $1.14 \%$ \\
\hline & Total & 176 & $100.00 \%$ \\
\hline & 1 & 109 & $61.93 \%$ \\
\hline & 2 & 47 & $26.70 \%$ \\
\hline P29 Retention plan or & 3 & 19 & $10.80 \%$ \\
\hline & 4 & 1 & $0.57 \%$ \\
\hline & Total & 176 & $100.00 \%$ \\
\hline & 1 & 123 & $69.89 \%$ \\
\hline & 2 & 36 & $20.45 \%$ \\
\hline P31 Recognition by & 3 & 16 & $9.09 \%$ \\
\hline & 4 & 1 & $0.57 \%$ \\
\hline & Total & 176 & $100.00 \%$ \\
\hline & 1 & 91 & $51.70 \%$ \\
\hline P32 Management to & 2 & 59 & $33.52 \%$ \\
\hline retain customers through & 3 & 23 & $13.07 \%$ \\
\hline the actions of the & 4 & 2 & $1.14 \%$ \\
\hline collaborators & 5 & 1 & $0.57 \%$ \\
\hline & Total & 176 & $100.00 \%$ \\
\hline & 1 & 94 & $53.41 \%$ \\
\hline & 2 & 55 & $31.25 \%$ \\
\hline P33 Plan of health & 3 & 26 & $14.77 \%$ \\
\hline & 4 & 1 & $0.57 \%$ \\
\hline & Total & 176 & $100.00 \%$ \\
\hline & 1 & 113 & $64.20 \%$ \\
\hline P34 Compensation to the & 2 & 43 & $24.43 \%$ \\
\hline partners according to the & 3 & 17 & $9.66 \%$ \\
\hline results with the creation & 4 & 2 & $1.14 \%$ \\
\hline of value & 5 & 1 & $0.57 \%$ \\
\hline & Total & 176 & $100.00 \%$ \\
\hline Motivational & & & \\
\hline Average 1.55 & & & \\
\hline Standard deviation 0.54 & & & \\
\hline
\end{tabular}


Table 14. Mann-Whitney U Test to measures differences in median

\begin{tabular}{|c|c|c|c|c|}
\hline & $\begin{array}{l}\text { Mann- } \\
\text { Whitney } \\
\text { U Test }\end{array}$ & $\begin{array}{l}\text { W-Wil- } \\
\text { coxon }\end{array}$ & $\mathrm{Z}$ & $\begin{array}{l}\text { Sig. } \\
\text { asymp- } \\
\text { totic } \\
\text { (bilat- } \\
\text { eral) }\end{array}$ \\
\hline $\begin{array}{l}\text { P1 Style of } \\
\text { organisational } \\
\text { culture }\end{array}$ & 1248.500 & 13183.500 & -2.28 & .022 \\
\hline $\begin{array}{l}\text { P2 Leadership } \\
\text { and management } \\
\text { support }\end{array}$ & 1604.000 & 1857.000 & -.47 & .637 \\
\hline $\begin{array}{l}\text { P3 Flexible } \\
\text { organisational } \\
\text { structure }\end{array}$ & 1684.500 & 13619.500 & -.04 & .963 \\
\hline $\begin{array}{l}\text { P4 Organisational } \\
\text { resources and } \\
\text { capacities }\end{array}$ & 1547.500 & 1800.500 & -.74 & .459 \\
\hline $\begin{array}{l}\text { P5 Style of } \\
\text { leadership and } \\
\text { management }\end{array}$ & 1560.500 & 1813.500 & -.69 & .485 \\
\hline $\begin{array}{l}\text { P6 Management } \\
\text { of the area of } \\
\text { human talent }\end{array}$ & 1518.500 & 13453.500 & -.92 & .353 \\
\hline $\begin{array}{l}\text { P7 Working } \\
\text { conditions }\end{array}$ & 1564.500 & 1817.500 & -.69 & .486 \\
\hline $\begin{array}{l}\text { P8 Organisational } \\
\text { climate }\end{array}$ & 1528.500 & 13463.500 & -.95 & .338 \\
\hline $\begin{array}{l}\text { P9 Working } \\
\text { conditions }\end{array}$ & 1668.000 & 1921.000 & -.15 & .874 \\
\hline $\begin{array}{l}\text { P10 } \\
\text { Self-improvement }\end{array}$ & 1669.000 & 13604.000 & -.13 & .896 \\
\hline P11 Labor surveys & 1585.000 & 13520.000 & -.59 & .554 \\
\hline $\begin{array}{l}\text { P12 Professional } \\
\text { growth }\end{array}$ & 1318.000 & 1571.000 & -2.27 & .023 \\
\hline $\begin{array}{l}\text { P13 Personal } \\
\text { growth }\end{array}$ & 1648.000 & 13583.000 & -.27 & .783 \\
\hline $\begin{array}{l}\text { P14 } \\
\text { Remuneration } \\
\text { policy }\end{array}$ & 1585.000 & 1838.000 & -.57 & .565 \\
\hline $\begin{array}{l}\text { P15 Scale of } \\
\text { acknowledgments }\end{array}$ & 1673.000 & 13608.000 & -.10 & .913 \\
\hline $\begin{array}{l}\text { P16 Labor } \\
\text { flexibility }\end{array}$ & 1681.500 & 1934.500 & -.06 & .947 \\
\hline $\begin{array}{l}\text { P17 Labor } \\
\text { happiness }\end{array}$ & 1650.000 & 1903.000 & -.26 & .794 \\
\hline $\begin{array}{l}\text { P18 } \\
\text { Self-realisation }\end{array}$ & 1560.500 & 13495.500 & -.75 & .453 \\
\hline
\end{tabular}

\begin{tabular}{|c|c|c|c|c|}
\hline $\begin{array}{l}\text { P19 Opportunity } \\
\text { of promotion }\end{array}$ & 1393.000 & 1646.000 & -1.70 & .088 \\
\hline $\begin{array}{l}\text { P20 Training } \\
\text { opportunities }\end{array}$ & 1526.000 & 1779.000 & -.98 & .326 \\
\hline $\begin{array}{l}\text { P21 Commitment } \\
\text { to the } \\
\text { organisation }\end{array}$ & 1586.000 & 1839.000 & -.57 & .565 \\
\hline $\begin{array}{l}\text { P22 Personal } \\
\text { attitude }\end{array}$ & 1424.000 & 1677.000 & -1.65 & .098 \\
\hline $\begin{array}{l}\text { P23 Policy of } \\
\text { loyalty to the } \\
\text { collaborators }\end{array}$ & 1507.500 & 1760.500 & -.95 & .337 \\
\hline $\begin{array}{l}\text { P24 Time for the } \\
\text { family }\end{array}$ & 1631.000 & 1884.000 & -.42 & .674 \\
\hline $\begin{array}{l}\text { P25 Respect for } \\
\text { diversity }\end{array}$ & 1421.500 & 1674.500 & -1.54 & .122 \\
\hline P26 Healthy living & 1602.000 & 1855.000 & -.49 & .618 \\
\hline $\begin{array}{l}\text { P27 Economic } \\
\text { bonuses }\end{array}$ & 1477.000 & 1730.000 & -1.07 & .281 \\
\hline $\begin{array}{l}\text { P28 } \\
\text { Compensation } \\
\text { and bonuses }\end{array}$ & 1657.000 & 13592.000 & -.18 & .853 \\
\hline $\begin{array}{l}\text { P29 Retention } \\
\text { plan of best } \\
\text { collaborators }\end{array}$ & 1585.000 & 13520.000 & -.56 & .571 \\
\hline $\begin{array}{l}\text { P30 Budget for } \\
\text { training }\end{array}$ & 1692.500 & 13627.500 & -.00 & .993 \\
\hline $\begin{array}{l}\text { P31 Recognition } \\
\text { by objectives }\end{array}$ & 1534.500 & 1787.500 & -.88 & .376 \\
\hline $\begin{array}{l}\text { P32 Management } \\
\text { to retain } \\
\text { customers } \\
\text { through the } \\
\text { actions of the } \\
\text { collaborators }\end{array}$ & 1603.500 & 1856.500 & -.44 & .655 \\
\hline $\begin{array}{l}\text { P33 Plan of health } \\
\text { policies }\end{array}$ & 1354.000 & 1607.000 & -1.68 & .092 \\
\hline $\begin{array}{l}\text { P34 } \\
\text { Compensation } \\
\text { to the partners } \\
\text { according to the } \\
\text { results with the } \\
\text { creation of value }\end{array}$ & 1529.000 & 1782.000 & -.87 & .384 \\
\hline
\end{tabular}

the need for subsequent analysis in the development of the items.

\subsection{Analysis of the Results of Concordance}

An analysis assesses the consistency of responses within a group of evaluators and between them, and, 
if appropriate, compares the responses with the values "pattern" or "reference" (also known as "standard values"). The analysis uses the ratings or ratings of the attributes. .37 In this sense, the Kappa index is traditionally used; it is an instrument designed by Cohen that adjusts the effect of chance in the proportion of the observed agreement and represents the maximum possible agreement or concordance, not due to chance. $\frac{38}{\text { The Kappa index }}$ related to the agreement that exhibits the observers, beyond the due to chance, with the potential agreement, also beyond the chance. The process of development of the index is to calculate the difference between the proportion, according to what has been observed, and the proportion, according to what was expected by chance. The numerator of the Kappa coefficient expresses the proportion of the observed as less than expected, while the denominator is the difference between total agreement and the expected proportion by chance. In conclusion, the Kappa corrects the agreement only by chance, as is the proportion of the agreement noted that exceeds the proportion by chance. If this value is equal to 1 , we would be faced with a situation in which the concordance is perfect ( $100 \%$ of total agreement or agreement), and, therefore, the proportion by chance is zero; when the value is 0 , there is total disagreement and then the expected proportion by chance is equal to the observed proportion. Table 15 presents the results of symmetric measures for each Kappa:

According to the results obtained in each of the associated answers to the experts consulted, the concordance is almost perfect, is between moderate and good. $\underline{39}$ Statistical methods for the evaluation of the consistency and reproducibility are dependent on the characteristics of the phenomenon to be studied and should be subject to a rigorous methodology. Your selection depends on the type of variable to be measured and the parameters that you want to evaluate.

\section{Conclusions}

From the empirical analysis, we found that for companies that are proposing that a strategic management of human talent it is necessary to achieve productivity and competitiveness in the sector of the economy that the company has stronger sales, bigger market share, and is looking to increase clients, who are valued and wellattended; this is achieved with satisfied employees in the emotional and labour dimensions.
Table 15. Symmetric measures

\begin{tabular}{|c|c|c|c|c|}
\hline Kappa & Value & $\begin{array}{c}\text { Asymptotic } \\
\text { standard } \\
\text { error }^{\mathrm{a}}\end{array}$ & $\begin{array}{l}\text { Approxi- } \\
\text { mate } T^{b}\end{array}$ & $\begin{array}{l}\text { Approxi- } \\
\text { mate } \\
\text { significance }\end{array}$ \\
\hline E 1 & 1.000 & 0.000 & 6.856 & 0.000 \\
\hline E 2 & 1.000 & 0.000 & 6.856 & 0.000 \\
\hline E 3 & 0.946 & 0.054 & 6.492 & 0.000 \\
\hline E 4 & 0.946 & 0.054 & 6.492 & 0.000 \\
\hline E 5 & 0.554 & 0.139 & 4.241 & 0.000 \\
\hline E 6 & 0.888 & 0.077 & 6.129 & 0.000 \\
\hline E 7 & 0.888 & 0.077 & 6.129 & 0.000 \\
\hline E 8 & 0.475 & 0.144 & 3.825 & 0.000 \\
\hline E 9 & 0.475 & 0.144 & 3.825 & 0.000 \\
\hline E 10 & 0.578 & 0.138 & 4.154 & 0.000 \\
\hline
\end{tabular}

In the statistical analysis of predictive explanatory type, it was found that the instrument was validated by experts; the responses of the test by employers and the results that were found in each of the statistical indices analysed allow to conclude that the model of emotional salary should be considered by the companies of any size or type of organisation, thus allowing to find the relationship between satisfaction, employment, and productivity; it is a way to find healthy companies in both the internal and external environments.

The significant results, which give validity to the test and to the relationship of the dimensions and items, showed a Cronbach's alpha of 0.0941 . That indicates an excellent result of all items identified, and a significance value big enough for this type of analysis. At the same time, the measure of Kaiser Permanente, Mayer and Olkin (KMO), by means of the Chi-square test, was able to demonstrate a superior outcome of 0.65 , which states that the factorial analysis applied is optimal in this case.

Defining an emotional wage policy in organisations allows to reduce levels of job dissatisfaction, rotation of staff, and medical disabilities caused by stress, tiredness, or by carrying out prolonged, time-consuming activities by the implementing partners; this implies that there are situations of dissatisfaction, frustration, and lack of interest in the work. With regard to the science, companies now have a model that may provide, according to their needs, an instrument for continuous improvement and a model that contributes to the logic of the humanised management, stressing that it was the 
result of the empirical evidence and construction, and is a phenomenon that has not been studied in depth.

\section{References}

1. Arango LFQ, Arias JDB. Salary model for the loyalty of employees in the search for a competitive organization. J Space. 2018 April;39(41):8-14.

2. Hernández GC, Valencia JCN, Giraldo CMÁ. Human resource management in Colombian businesses: its characteristics, challenges, and contributions an approach to an integral system. Manag Noteb. 2010 May;23(41): 13-36.

3. Santos AC. Human talent management and knowledge. Ecoe Ediciones, 2010.

4. Naranjo OLJ. Management of human talent in micro, small and medium enterprises linked to the Expopyme program of the North University in the clothing and food sectors. Think Manag. 2005 June;(18):103-37.

5. Rodriguez MAC, Bermùdez EIZ, Vasquez HGE. Human talent management in the PYMES. J Publ. 2016 July;3(7):438-48.

6. Prieto EA, Cepeda A, Urribarrí M. Human management as a competitive strategy in mass-consumer companies. J Res Cent Admin Sci Manag. 2012 September;9(1):90-100.

7. Camejo AJ. Human talent management and social responsibility in the 21 st century business organizations (a look from the context of globalization). J Manag Polit Soc. 2015 April;8:57-76.

8. Romano A. The humanization of training in service delivery organizations. Case Death Manag J Negot, 2015 October;10(30):6-13.

9. Fuentes P. Internal marketing operations: endomarketing model proposal. J Perspect. 2009 September;23:189-231.

10. Barragán J, Castillo J, Villalpando P, Guerra P. Efficient employee retention strategies: strategic importance of employee loyalty in international organizations. J Bus Innov. 2009 June;6(1):33-43.

11. Satisfied employees, loyal customers. [cited 2018 August 05]. https://repositorio.iberopuebla.mx/bitstream/handle/ 20.500.11777/1669/Empleados+Satisfechos,+Clientes+Feli ces.pdf;jsessionid=0F328388AA10FD338C8C5092184282 D7? sequence $=1$.

12. Carazo J. Bancaja loyaltys its employees through internal commitment. Hum Cap. 2007 October;206:28-34. http:// www.gref.org/nuevo/articulos/art_260107_bcj.pdf.

13. Pérez F. Growth and competitiveness. The challenges of recovery. Spain: Rubes Editorial; 2013.

14. Schultz T. Investment in man: an economist's view. Soc Serv Rev. 1959 April;33:109-17.
15. Torres J. Approaches to measuring the impact of human capital management on business outcomes. J Thought Manag. 2005 February;18:151-76.

16. Aira M. Institutions and their impact on organizational behavior. J Negot. 2016 October;11(33):99-111.

17. Alonso V. Critical factors of success and assessment of the competitiveness of tourist destinations. Tour Stud Perspect. 2010 March;19(2):205-7.

18. Atkinson J. The flexible firm and the shape of jobs to come. Labour market issues; 1984.

19. Barbosa R. What strategic behaviors favor innovation in the organization? J Manag Innov. 2009 April;6(3).145-62.

20. Business growth cases. Medellín, Colombia: Universitary Foundation María Cano. [cited 2018 Sep 10]. http:// www.fumc.edu.co/documentos/elibros/Casos\%20de\%20 crecimiento\%20empresarial.pdf.

21. Business structure.[cited 2018 Aug 15]. https:// ww w.cam a ramedellin.com.co/biblioteca/ estructura-empresarial-2018.

22. Cardona D, Zambrano R. Review of organizational climate assessment tools. J Manag Stud. 2014 September;30(131):184-9.

23. ChávezN.Competencymanagementand exerciseofbusiness coaching, two internal strategies for the organization. Thought Manag Mag. 2012 October;33:142-61.

24. Cuadra A, Veloso C. Leadership, climate and job satisfaction in organizations. Universum. 2007 September;22(2):40-56.

25. Emotional salary as a strategy for durability in the best performing collaborators in Industria de Alimentos Daza S.A.S. [cited 2018 Sep 18]. http://repository.lasalle.edu.co/ handle/10185/17838.

26. Escobar M. Labour skills: the labour strategy for the competitiveness of organizations? Manag Stud Icesi. 2005 October;96:31-55.

27. Ibarra M, González L. Labour flexibility as a competitiveness strategy and its effects on the economy, business and labour market. J Account Manag. 2009 April;231:33-52.

28. Level of job satisfaction of employees of the municipal mayor of Celia Risaralda.Technological University of Pereira, Colombia. [cited 2018 Sep 20]. https://docplayer. es/4310167-Nivel-de-satisfaccion-laboral-de-losempleados-de-la-alcaldia-municipal-de-la-celia-risaralda. html.

29. Kerlinger FN, Lee HB. Behavioral research. Social science research methods. Mexico: McGraw-Hill; 2002.

30. López J. Job motivation and human resources management in Frederick Herzberg theory. J Res Fac Admin Sci. 2005 March;8(15):25-36.

31. Lozano L. Human talent, a successful strategy, in cultural enterprises. J Sch Bus Admin. 2007 October;60:147-64. 
32. Marzo M, Pedraja M, Rivera P. Skills and competencies demanded by the labour market. J Icade. 2008 April;73:347-63.

33. Puerto D. Globalization and business growth through internationalization strategies. J Thought Manag. 2010 February;28:171-95.

34. Vesga J. The types of employment hire and its implications in the psychological contract. J Psychol Thought. 2011 July;9(16):171-82.

35. Welch S, Comer JC. Quantitative methods for public administration: techniques and application. Homewood, United States: Brooks/Cole; 1988.
36. Match and consistency help. [cited 2018 Oct 22]. https:// www.sergas.es/Saude-publica/Documents/1894/Ayuda_ Epidat4_Concordancia_y_consistencia_Octubre2014.pdf.

37. Picado F. Attribute Concordance analysis. J Technol Exec. 2008 July;21(4):29-35.

38. Cortés É, Rubio J, Duarte H. Statistical methods of assessing the concordance and reproducibility of diagnostic tests. Colomb J Obstet Gynecol. 2010 April;61(3):247-55.

39. Cerda J, Villarroel L. Evaluation of inter-observer concordance in paediatric research: kappa coefficient. Chil Paediatr Rev. 2008 June;79(1):54-8. 